\title{
The Effect of Excess Dietary Sucrose on Growth, Blood Pressure, and Metabolism in Developing Sprague-Dawley Rats
}

\author{
S. HULMAN AND B. FALKNER \\ Neonatology Division, Department of Pediatrics, Albert Einstein Medical Center, Philadelphia, \\ Pennsylvania 19141-3098 [S.H.], and Department of Pediatrics, Medical College of \\ Pennsylvania, Philadelphia, Pennsylvania 19129 [B.F.]
}

\section{ABSTRACT}

To determine the effects of sucrose-enriched feeds on somatic growth, blood pressure development, and insulinstimulated glucose metabolism, Sprague-Dawley rat pups $(n=94)$ were randomly assigned at weaning $(3 \mathrm{wk})$ to a control diet $(15 \%$ sucrose, by calories, $n=48)$ or an isocaloric diet in which starch is replaced by sucrose $(66 \%$ sucrose, by calories, $n=46$ ). Weight and blood pressure were followed until $13 \mathrm{wk}$. Chronic catheters were placed in a subset of male animals $(n=13)$, fasting glucose production was measured, and euglycemic hyperinsulinemic clamps were performed while the rats were in the conscious, nonstressed state. There was no difference in weight gain between control and sucrose rats in each sex group. Blood pressure in sucrose rats was significantly higher than in control rats after 4 wk of diet $(7$ wk of age, $p<0.001)$ in both

Insulin resistance is defined as a suboptimal biologic response to insulin (1). Data from epidemiologic studies have shown an association of hyperinsulinemia (indicating insulin resistance) with hypertension, independent of obesity and non-insulin-dependent diabetes mellitus (2, 3 ). Clinical investigations on insulin-mediated glucose metabolism using the euglycemic hyperinsulinemic clamp technique $(4,5)$ have confirmed in nonobese, nondiabetic patients with essential hypertension the presence of both hyperinsulinemia and insulin resistance in peripheral tissue.

Recent experimental studies have shown that hypertension, without obesity, can be induced in 8- to 9-wk-old Sprague-Dawley rats after only 2 wk of a diet in which complex carbohydrate is replaced with fructose $(6,7)$. The presence of insulin resistance, as measured by the insulin suppression test, is concurrent with blood pressure elevation in these rats. Because of the preponderance of sugar in contemporary American diets $(8,9)$,

Received October 12, 1993; accepted February 16, 1994.

Correspondence: S. Hulman, M.D., Division of Neonatology, Albert Einstein Medical Center, 5501 Old York Rd., Philadelphia, PA 19141-3098. sex groups and persisted for the duration of sucrose-enriched feeds. Insulin resistance was confirmed in sucrose rats with the euglycemic hyperinsulinemic clamp technique. In juvenile rats that have no genetic predisposition to hypertension, excess dietary sucrose induced high blood pressure without obesity. Sucrose feeding also induced insulin resistance. The sucrose-fed Sprague-Dawley weanling rat provides a model of diet-induced juvenile-onset hypertension with insulin resistance. (Pediatr Res 36: 95-101, 1994)
GSA, glucose specific activity
ANOVA, analysis of variance
$\mathbf{R}_{\mathbf{a}}$, rate of appearance
$\mathbf{R}_{\mathbf{d}}$, rate of disappearance

Abbreviation

especially those of children (10), we wished to determine the effects of substituting this dietary constituent for complex carbohydrate on adiposity, blood pressure, and insulin-stimulated glucose metabolism in developing rats. Because young rats are significantly more insulinsensitive than older rats (11), it was not obvious that the imposition of isocaloric sucrose-enriched feeds would result in elevated blood pressure and insulin resistance in weanling rats.

\section{METHODS}

\section{Animal Protocol}

Animal protocols were approved by the Institutional Animal Care and Utilization Committee of the Medical College of Pennsylvania, Philadelphia, which adheres to the guidelines for proper animal care found in the $\mathrm{NIH}$ Guide for the Care and Use of Laboratory Animals.

Pregnant Sprague-Dawley rats were obtained from Taconic Farms, Germantown, NY. The pups were nursed for $3 \mathrm{wk}$ and separated from the dam on $\mathrm{d} 21$. At weaning, they were separated by sex and randomized to 
receive control rat food or rat food in which starch (dextrin) was replaced with sucrose (components of the diet are described in Table 1). Control and sucroseenriched diet pellets were isocaloric $(15.1 \mathrm{~kJ} / \mathrm{g}$, or 3.60 $\mathrm{cal} / \mathrm{g}$ ). The animals had free access to water. They were housed in a room with a 12-h light/dark cycle. Food consumption was measured and caloric intake was calculated three times per week. Animals were weighed weekly. When the pups weighed about $75 \mathrm{~g}$, they began training for indirect tail-cuff blood pressure determination (model 99, IITC Life Sciences Inst., Woodland Hills, CA). Validation of blood pressure determination by tail plethysmography in rats has been described by Buñag (12). The instrument had previously been validated in our laboratory with intraarterial measurements. Stable blood pressure measurements were achieved by $6 \mathrm{wk}$ of age. Thereafter, blood pressure and weight were determined on the same day, once per week. The weekly blood pressure for each animal that was used in the statistical analysis was the mean of four to six readings per session.

To evaluate insulin sensitivity after $10 \mathrm{wk}$ of diet (age $13 \mathrm{wk}$ ), insulin-stimulated glucose metabolism was measured with the euglycemic hyperinsulinemic clamp. A subset of male animals underwent surgery for implantation of chronic catheters. Females were not used for the clamp study because their relative small size at $13 \mathrm{wk}$ $(250 \mathrm{~g})$ resulted in great difficulty with catheter implantation. After intraperitoneal anesthesia with acepromazine, ketamine, and xylazine, one small $(0.5-\mathrm{cm})$ midline incision was made, which permitted catheterization of the internal jugular vein (Silastic medical grade, Becton Dickinson, Parsippany, NJ) and the contralateral carotid artery (PE 10, Becton Dickinson). The catheters were exteriorized to the ventral surface of the neck and sealed with a viscous solution of polyvinylpyrrolidone (PVP-10, Sigma, St. Louis, MO). The catheters required no further care before surgery, until the time of the clamp study, when the PVP-10 was slowly flushed through the catheters to establish patent access to the vessels. The animals recovered from surgery in a neonatal incubator, which prevented postoperative hypothermia.

Table 1. Diet specifications*

\begin{tabular}{lccccc}
\hline & \multicolumn{2}{c}{ Control } & & \multicolumn{2}{c}{ Sucrose } \\
\cline { 2 - 3 } \cline { 5 - 6 } & $\begin{array}{c}\% \text { by } \\
\text { calories }\end{array}$ & $\begin{array}{c}\% \text { by } \\
\text { weight }\end{array}$ & & $\begin{array}{c}\% \text { by } \\
\text { calories }\end{array}$ & $\begin{array}{c}\% \text { by } \\
\text { weight }\end{array}$ \\
\hline Protein & 19.8 & 18.0 & & 20.0 & 18.0 \\
Fat & 14.0 & 5.6 & & 13.9 & 5.6 \\
Fiber & 0 & 10.0 & & 0 & 9.0 \\
Carbohydrate & & & & \\
$\quad$ Dextrin & 47.7 & 43.5 & & 0 & 0 \\
$\quad$ Sucrose & 18.6 & 16.9 & & 66.0 & 59.4 \\
$\quad$ Total & 66.3 & 60.4 & & 66.0 & 59.4 \\
Digestible energy (kcal/g) & & 3.6 & & 3.6 \\
Ca & & 0.6 & & 0.6 \\
Na & & 0.2 & & 0.2 \\
$\mathrm{Cl}$ & & 0.2 & & 0.2 \\
\hline
\end{tabular}

* There are no differences in the two diets other than amount of sucrose.

\section{Measurement of Hepatic Endogenous Glucose Production and Insulin-Stimulated Glucose Metabolism}

Each rat was studied after it had regained preoperative weight, which was usually $72 \mathrm{~h}$ after surgery. The rat was fully conscious, unrestrained, and remained quiet for the duration of the study. After a 12-h fast, measurement of fasting endogenous glucose production was made with the tracer dilution method before the imposition of euglycemic hyperinsulinemia. A primed constant infusion of tritiated glucose (prime $=1 \mu \mathrm{Ci}$, infusion $=0.1 \mu \mathrm{Ci}$ / min of D- $6-{ }^{3} \mathrm{H}$-glucose, New England Nuclear, Boston, MA) was delivered through the arterial catheter and continued for $60 \mathrm{~min}$ (13). During the final $10 \mathrm{~min}$ of $6-{ }^{3} \mathrm{H}$-glucose infusion, three samples were withdrawn, and the plasma was isolated by centrifugation. Portions of the three plasma samples were analyzed immediately for glucose concentration by the glucose oxidase method (Glucostat, model 27, Yellow Springs Instrument Co., Yellow Springs, $\mathrm{OH}$ ). Another portion of the plasma sample was used for the measurement of GSA, and the remainder was immediately frozen at $-20^{\circ} \mathrm{C}$ for subsequent RIA of plasma insulin concentration (see below).

Euglycemic hyperinsulinemia was then instituted with a simultaneous infusion of insulin (regular human insulin, Eli Lilly, Indianapolis, IN) at about $30 \mathrm{pmol} / \mathrm{kg} / \mathrm{min}(4.0$ $\mathrm{mU} / \mathrm{kg} / \mathrm{min})$ and glucose (20\% dextrose), according to previously reported methods (14). Infusion of tritiated glucose continued during euglycemic hyperinsulinemia to determine the effect of hyperinsulinemia on endogenous glucose production. Euglycemic hyperinsulinemia was maintained for $90 \mathrm{~min}$. During the final $10 \mathrm{~min}$, three samples were withdrawn for measurement of plasma GSA and insulin concentration, as well as plasma glucose concentration.

\section{Assays}

Glucose. Plasma glucose concentration was measured with the glucose oxidase method, as noted above. The precise concentration of glucose in the $20 \%$ dextrose infusate was measured, and this concentration was used to determine glucose infusion rate.

Insulin. Plasma insulin was measured with RIA (DPC Coat-A-Count, Los Angeles, CA), using a human standard. Rat insulin and human insulin differ by only three amino acid residues, so cross-reactivity of the human antibody and rat antigen should be present. To ensure that cross-reactivity was occurring, RIA of serial dilutions of fasting rat plasma was performed with human antibody and compared to a human insulin standard curve. There was parallel displacement of the rat plasma curve, indicating cross-reactivity of the two species. Consequently, human standard can be used for both fasting rat plasma, as well as "clamped" rat plasma. Plasma insulin concentration is expressed as $\mathrm{pmol} / \mathrm{L}$.

GSA. GSA was determined with the Somogyi method (15). Briefly, rat plasma samples $(0.05 \mathrm{~mL})$ were deproteinized with $0.100 \mathrm{~mL}$ each of $0.1 \mathrm{~N} \mathrm{ZnSO}_{4}$ and $0.1 \mathrm{~N}$ 
$\mathrm{Ba}(\mathrm{OH})_{2}$. After a 30-min room temperature incubation, $0.05 \mathrm{~mL}$ of supernatant was dried overnight (to evaporate tritiated water). The samples were reconstituted with $0.05 \mathrm{~mL}$ of distilled water. After addition of $10 \mathrm{~mL}$ of Ecolume (ICN, Irvine, CA), a water-soluble biodegradable scintillation cocktail, counts were determined in a liquid scintillation counter (Beckman Instruments, Fullerton, CA). After correction for quenching, $\mathrm{cpm} / \mathrm{mL}$ were determined for each sample. GSA in the fasting state was calculated by determining the quotient of corrected counts $/ \mathrm{mL}$ and glucose concentration from the three samples withdrawn at the end of the first $90 \mathrm{~min}$. The calculation of glucose turnover (or $R_{a}$ ) in the fasting state was performed with the equation of Steele (16) $\left(R_{a}\right.$ $=$ infusion rate of tracer/specific activity of tracer) and was based on the assumption of achievement of a steady state. $R_{a}$ is expressed in $\mathrm{mmol} / \mathrm{kg} / \mathrm{min}$. It is recognized that the Steele equation (16) underestimates the rate of glucose turnover in the fasting state (17). Because some tritium from $6-{ }^{3} \mathrm{H}$-glucose is lost to lactate, underestimation of $R_{a}$ arises from the contribution of counts derived from tritiated lactate, which was not chromatographically removed in this protocol. According to Dunn et al. (18), $19 \%$ of tritium counts are lost from glucose to lactate when $6-{ }^{3} \mathrm{H}$-glucose is used. However, in the study reported here, all samples were processed in the same way, so the error is systematic and the same in both feed groups.

GSA during hyperinsulinemia was determined from the three samples withdrawn at the end of the clamp, with the methods described above. Hepatic endogenous glucose production during euglycemic hyperinsulinemia was calculated as the difference between the $R_{d}$ of glucose $\left(R_{d}=\right.$ infusion rate of tracer/specific activity of tracer) and the glucose infusion rate required to maintain euglycemia. It is recognized that this method underestimates the $R_{d}$ of glucose during euglycemic hyperinsulinemia because GSA is contaminated with tritiated lactate (see above), but as with the determination of $R_{a}$ described above, all samples were processed in the same way, so the systematic error is the same in both strains. This underestimation of $R_{d}$ may lead to negative numbers if glucose infusion rate exceeds $R_{d}$, which is interpreted as complete suppression of hepatic endogenous glucose production (19).

\section{Statistical Methods}

Mean blood pressure, weight, and fasting metabolic variables in the two feed groups were compared with the $t$ test. Metabolic variables during euglycemic hyperinsulinemia were analyzed with two-way ANOVA, followed by Scheffe's test for pairwise comparisons. Results are expressed as mean $\pm \mathrm{SD}$.

\section{RESULTS}

Data are available from 50 males and 44 females. Males included 26 fed the control diet and 24 fed the sucrose diet. Females were randomized to 22 fed the control diet and 22 fed the sucrose diet.

Somatic growth. Somatic growth for both control and sucrose males and females is depicted in Figure 1. Although weight and weight gain were significantly greater in males than in females, within sex groups there was no difference in growth conferred by type of diet (two-way ANOVA). Total food consumption was also the same in both male groups and in both female groups; therefore, the only difference between the feed groups was intake of sucrose. Caloric, protein, fat, and mineral intake were the same between the feed groups.

Blood pressure. Figure 2 depicts mean blood pressure for all four groups of rats during the 10-wk experimental period. The upper panel depicts both male feed groups; the lower panel, both female feed groups. Several findings are apparent from this figure: 1) Both male groups (upper panel), as well as sucrose females (lower panel), demonstrated a significant rise in blood pressure over the 10-wk diet period (ANOVA: control males: $F=15.7, p<$ 0.0001; sucrose males: $F=31.6, p<0.0001$; sucrose females: $F=8.41, p<0.0001$ ). Control females did not show a statistically significant rise in blood pressure over the 10 -wk diet period $(F=1.61, p=0.12)$. 2) The rise in blood pressure in sucrose males was significantly greater than in control males (two-way ANOVA, $p<0.0001$ ). Sucrose females had significantly greater blood pressure than control females from wk 7 through 13, despite a decline in blood pressure in sucrose females after 9 wk (two-way ANOVA, $p<0.0001$ ). 3) Blood pressure in sucrose males and sucrose females was not different from wk 4 through 10 . After wk 10, blood pressure in sucrose males was significantly higher than in sucrose females $(p$ $<0.005)$.

Insulin-stimulated glucose metabolism. Fasting and insulin-stimulated glucose metabolism (clamp) studies were performed in 13 males (seven control, six sucrose) at age

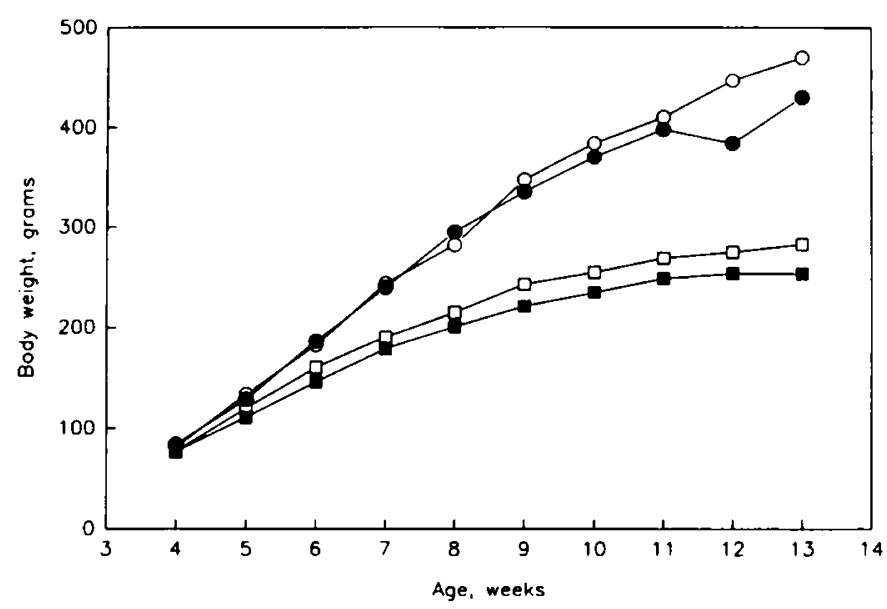

Figure 1. Somatic growth. Mean weekly body weights of four groups of rats. Filled squares, control females; open squares, sucrose females; filled circles, control males; open circles, sucrose males. Despite a sucrose-enriched diet, sucrose-fed animals (in each sex group) had the same growth curve. 

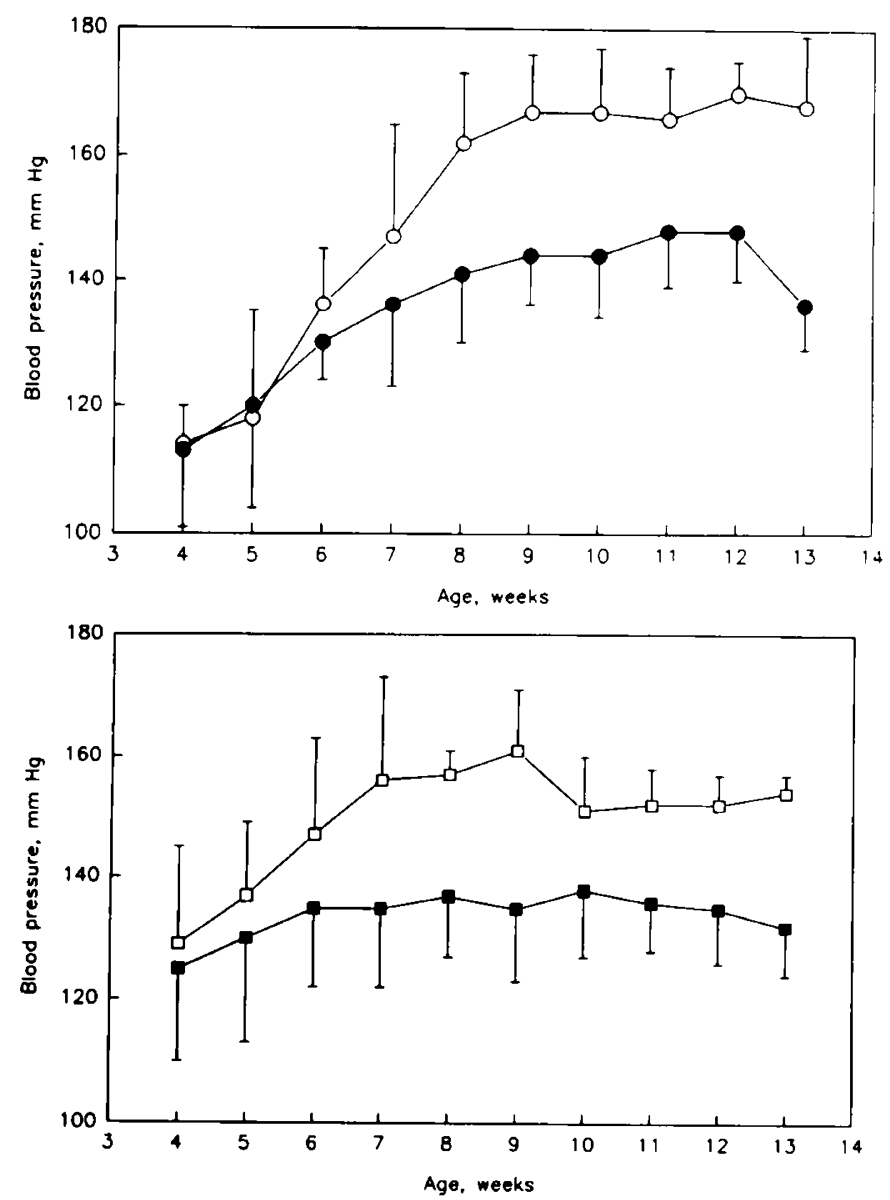

Figure 2. Blood pressure in male (upper panel) and female (lower panel) rats. Mean weekly blood pressure $\pm 1 \mathrm{SD}$. Symbols are the same as Figure 1. In each sex, mean weekly blood pressure in both diet groups increased significantly from wk 4 to 13 . Mean blood pressure in sucrose-fed males was significantly greater than in control males from wk 7 through 13 (ANOVA, $p<0.0001$ ). Mean blood pressure in sucrose-fed females was significantly greater than in control females from wk 7 through 13, despite decreasing means in sucrose females during wk 10 through 14 (ANOVA, $p<0.0001$ ).

13 wk. Fasting data are presented in Table 2. Mean fasting glucose (control versus sucrose: $6.7 \pm 0.9$ versus $7.2 \pm 0.9 \mathrm{mmol} / \mathrm{L}, 120.3 \pm 14.9$ versus $128.6 \pm 16.4$ $\mathrm{mg} / \mathrm{dL}$ ) and insulin concentration (control versus sucrose: $191 \pm 86$ versus $183 \pm 60 \mathrm{pmol} / \mathrm{L}, 26.6 \pm 12.0$ versus $25.5 \pm 8.4 \mu \mathrm{U} / \mathrm{mL}$ ) were not significantly different between control and sucrose-fed groups. There was no

Table 2. Fasting metabolic data*

\begin{tabular}{lcc}
\hline & $\begin{array}{c}\text { Control } \\
(n=7)\end{array}$ & $\begin{array}{c}\text { Sucrose } \\
(n=6)\end{array}$ \\
\hline Fasting plasma glucose & & \\
$\mathrm{mmol} / \mathrm{L}$ & $6.7 \pm 0.9$ & $7.2 \pm 0.9$ \\
$\mathrm{mg} / \mathrm{dL}$ & $120.3 \pm 14.9$ & $128.9 \pm 16.4$ \\
Fasting plasma insulin & & \\
$\mathrm{pmol} / \mathrm{L}$ & $191 \pm 86$ & $183 \pm 60$ \\
$\mu \mathrm{U} / \mathrm{mL}$ & $26.6 \pm 12.0$ & $25.5 \pm 8.4$ \\
$\mathrm{R}_{\mathrm{a}}^{\mathrm{mmol} / \mathrm{kg} \mathrm{min}}$ & & \\
$\mathrm{mg} / \mathrm{kg} \mathrm{min}$ & $0.031 \pm 0.015$ & $0.045 \pm 0.020$ \\
$\quad 5.5 \pm 2.7$ & $8.1 \pm 3.6$ \\
\hline
\end{tabular}

* Mean \pm SD. difference in $\mathrm{R}_{\mathrm{a}}$ of glucose between the groups (control versus sucrose: $0.031 \pm 0.015$ versus $0.045 \pm 0.020 \mathrm{mmol} /$ $\mathrm{kg} / \mathrm{min}, 5.5 \pm 2.7$ versus $8.1 \pm 3.6 \mathrm{mg} / \mathrm{kg} / \mathrm{min}$ ). However, because lactate was not chromatographically removed from plasma samples, specific activity was overestimated, leading to an underestimation of $R_{a}$. Additionally, sucrose feeding stimulates a high flow of phosphorylated fructose metabolites through the glycolytic pathway, resulting in increased lactate concentration (20). Compared with control samples, there could be further underestimation of $R_{a}$ in samples derived from sucrose-fed rats. Our data show that $R_{a}$ was somewhat greater in sucrose rats compared with controls; however, the difference was not statistically significant, with comparable standard deviations in both groups. Furthermore, despite the potential errors in the measurement of glucose production, the data reported here are consistent with earlier reports on conscious, chronically catheterized rats $(13,21)$. The data also indicate that both groups of animals did not experience a stress response.

Table 3 presents clamp metabolic data. Clamp plasma glucose and insulin concentrations were statistically similar in both groups; however, clamp plasma glucose concentration was more variable in the sucrose-fed animals than in the control-fed animals. During the clamp, tight control of plasma glucose concentration was more difficult in the sucrose-fed animals than in the controls, because the animals did not recover rapidly from an overdetermination of the glucose infusion rate. The comparative lack of rapid recovery in control of clamped glucose concentration may have been the result of reduced insulin-stimulated glucose utilization in the sucrose-fed animals.

The glucose infusion rate required to maintain euglycemia was significantly lower in the sucrose-fed animals (control versus sucrose: $0.143 \pm 0.050$ versus $0.077 \pm$ $0.030 \mathrm{mmol} / \mathrm{kg} / \mathrm{min}, 25.9 \pm 9.5$ versus $13.8 \pm 5.6 \mathrm{mg} / \mathrm{kg} /$ $\mathrm{min})$. The marked difference in both whole-body glucose utilization and the glucose infusion rate confirms the presence of insulin resistance in the sucrose-fed animals. The glucose infusion rate is an index of whole-body glucose utilization. However, in this study, to measure total glucose production, or $\mathrm{R}_{\mathrm{d}}, 6-{ }^{3} \mathrm{H}$-glucose was also infused during euglycemic hyperinsulinemia. $R_{d}$ was uniformly lower than the glucose infusion rate (data not

Table 3. Clamp metabolic data*

\begin{tabular}{lccc}
\hline & Control & Sucrose & $p$ \\
\hline Clamped plasma glucose & & & \\
$\mathrm{mmol} / \mathrm{L}$ & $6.3 \pm 0.5$ & $6.9 \pm 3.0$ & $\mathrm{NS}$ \\
$\mathrm{mg} / \mathrm{dL}$ & $113.3 \pm 9.8$ & $124.5 \pm 53.8$ & \\
$\mathrm{Clamped}$ plasma insulin & & & \\
$\mathrm{pmol} / \mathrm{L}$ & $979 \pm 352$ & $873 \pm 552$ & $\mathrm{NS}$ \\
$\mu \mathrm{U} / \mathrm{mL}$ & $136.5 \pm 49.0$ & $121.7 \pm 77.0$ & \\
$\mathrm{Glucose}$ infusion rate & & & \\
$\mathrm{mmol} / \mathrm{kg} / \mathrm{min}$ & $0.143 \pm 0.050$ & $0.077 \pm 0.030$ & 0.0196 \\
$\mathrm{mg} / \mathrm{kg} / \mathrm{min}$ & $25.9 \pm 9.5$ & $13.8 \pm 5.6$ & \\
\hline
\end{tabular}

* Mean \pm SD. 
shown), so that the difference between total production $\left(R_{d}\right)$ and the glucose infusion rate (or residual hepatic endogenous glucose production) was less than zero. This finding has no physiologic meaning but is frequently reported in other clamp studies and has been interpreted to indicate complete suppression of hepatic endogenous glucose production (19). There are several possible causes for underestimation of $R_{d}$ during euglycemic hyperinsulinemia. They are 1) tracer recycling, resulting in overestimation of GSA; 2) distinction in metabolism of labeled and unlabeled glucose; and 3) methodologic errors such as the "steady state" during euglycemic hyperinsulinemia being unstable; inadequate removal of tritium-labeled water, causing overestimation of GSA; and the presence of tritium-labeled three-carbon metabolites (lactate), causing overestimation of GSA.

\section{DISCUSSION}

This study demonstrates that consumption of a diet in which complex carbohydrate has been replaced by sucrose causes both elevated blood pressure and insulin resistance in juvenile rats with no genetic predisposition to either condition. These findings have been reported in adult rats fed either a sucrose- or fructose-enriched diet $(6,7)$. It was not obvious, however, that juvenile Sprague-Dawley rats would be similarly affected by a sucrose diet, because under more normative diet conditions, rat pups are highly insulin sensitive (21).

The control diet and the sucrose-enriched diet were similar in all respects, specifically total carbohydrate content; sodium, potassium, and calcium content; and caloric content. The two groups of animals consumed similar daily amounts of diet per $\mathrm{kg}$ of body weight; therefore, the only dietary difference was carbohydrate calories provided by sucrose instead of starch (dextrin).

Although blood pressure increased with increasing age and body weight in all four diet groups, higher blood pressures were clearly correlated with the sucrose diet in both males and females (Fig. 2). The higher blood pressure cannot be explained by greater total body weight in the sucrose-fed animals, because there was no difference in weight between control-fed and sucrose-fed rats in each sex group. Body composition was not examined; thus, it is not known if sucrose feeding in weanling rats resulted in a greater percentage of adipose tissue at the expense of other tissues. This is relevant because increased adipose mass has long been associated with decreased insulin-stimulated glucose utilization and insulin resistance (22) and with elevation in blood pressure (23). There are other reports of body composition analyses on rats fed sucrose-enriched diets. Storlien et al. (24) have shown that there are no changes in body composition when 8-wk-old male Wistar rats are maintained on a high-sucrose diet for $4 \mathrm{wk}$. In a similar protocol, Thorburn et al. (25) found no change in total body composition, or in brown adipose mass, after a 4-wk sucroseenriched diet. Our data are consistent with those of others indicating that increased body mass and increased adipose mass are unlikely explanations for insulin resistance and hypertension that results from a sugar-enriched diet fed to young rats.

Compensatory hyperinsulinemia counteracts impaired peripheral insulin-stimulated glucose utilization and impaired suppression of glucose production by the liver (26). The degree of hyperinsulinemia is an index of the severity of insulin resistance and can be linked to hypertension by several potential mechanisms. DeFronzo (27) showed that hyperinsulinemia results in retention of sodium by the distal tubules of the kidney, which can induce increased intravascular volume and hypertension. In young adults, Falkner et al. (28) demonstrated an association of plasma insulin concentration and blood pressure sensitivity to sodium. In fructose-fed rats, Hwang et al. (29) found elevated concentrations of atrial natriuretic factor and decreased concentrations of aldosterone, findings that are also consistent with a volumeoverload mechanism for hypertension.

Another possible link between hyperinsulinemia and elevated blood pressure is the effect of insulin on the sympathetic nervous system. Young and Landsberg (30) demonstrated a significant increase in norepinephrine turnover in the hearts of Sprague-Dawley rats during sucrose feeding. This effect was abolished during ganglionic blockade, indicating that it was centrally mediated. Although plasma glucose and insulin concentrations were not measured, the experimental protocol relates aberrant metabolism to increased sympathetic nervous system activity. A study in humans that also indicates that hyperinsulinemia in the absence of hypoglycemia may stimulate sympathetic nervous system activity was reported by Anderson et al. (31), who demonstrated an increase in peripheral nerve discharge during euglycemic hyperinsulinemia.

These hypothetical links between hyperinsulinemia and elevated blood pressure may not be entirely relevant in the study reported here, because the rats did not develop fasting hyperinsulinemia, despite $10 \mathrm{wk}$ of sucrose-enriched feeds. The lack of fasting hyperinsulinemia may be caused by unimpaired insulin clearance by peripheral musculature, despite decreased insulinstimulated glucose utilization. It should be pointed out that the sugar-fed animals in the studies of Storlien et al. (24) or Thorburn et al. (25) also had normal fasting insulin concentrations. Normal fasting insulin concentrations in these sugar-fed rats do not rule out alimented hyperinsulinemia, that is, hyperinsulinemia after ingestion of food. Alimented hyperinsulinemia could be detected with oral glucose tolerance tests, which were not performed in this study.

Earlier work $(24,25)$ described both the liver and peripheral tissue as the site of insulin resistance in the sugar-fed rat. Our study suggests, but does not prove, that hyperinsulinemia completely suppresses hepatic endogenous glucose production. Suppressible hepatic endogenous glucose production implicates peripheral tissue 
(skeletal muscle) as the site of insulin resistance. However, because $R_{d}$ was numerically less than the glucose infusion rate, endogenous hepatic glucose production could not be definitively calculated.

The study reported here is unique because it demonstrates the effect of dietary sugar on highly insulinsensitive animals. Both clinical $(32,33)$ and experimental studies in mammals (34-36) have demonstrated insulin resistance during the immediate newborn period. However, perinatal insulin resistance is short-lived. Issad $e t$ al. (37) have reported that insulin resistance in newborn (Wistar) rat pups (21) is replaced by a significant increase in insulin sensitivity by $28 \mathrm{~d}$ of life. With the euglycemic hyperinsulinemic clamp technique, these investigators determined that insulin-stimulated glucose metabolism in 28-d-old weanling Wistar anesthetized rats was approximately $0.194 \mathrm{mmol} / \mathrm{kg} / \mathrm{min}(35 \mathrm{mg} / \mathrm{kg} / \mathrm{min})$, which is approximately $40 \%$ higher than that reported here in our study of 12- to 14-wk-old control-fed rats. When the studies of Issad et al. are considered with our data in this report, it seems that insulin-resistant newborn rat pups mature into highly insulin-sensitive rats by $28 \mathrm{~d}$ of life. Insulin sensitivity then decreases with increasing age. Using the insulin suppression test to compare insulinstimulated glucose metabolism between 6-wk-old, 16-wkold, and 52-wk-old Sprague-Dawley rats, Narimiya et al. (11) showed that the younger animals are highly insulinsensitive compared with the older animals. However, our data from the study reported here clearly indicate that very young rats are vulnerable to the metabolic effects of excess dietary sugar despite their highly insulin-sensitive status.

The adverse effect of excess dietary sugar on insulinstimulated glucose metabolism in young animals has clinical relevance. Although examinations of dietary patterns in young Americans are typically focused on electrolyte and fat intake, some data on sugar intake are available. Both the Bogalusa Heart Study data (38) and the NHANES II data (39) demonstrate that in American children from 2 to $17 \mathrm{y}$ of age carbohydrates compose about half the caloric intake. They also found that sucrose composed 18 to $22 \%$ of total caloric intake, or almost half the carbohydrate intake. Similar findings were reported by Michel et al. (10), who studied dietary patterns in urban adolescents and found a sugar intake greater than $20 \%$ of total calories. These reports indicate that young Americans consume almost double the recommended daily amount of sugar (36). Such diets may contribute to the onset of insulin resistance and elevated blood pressure in the young, even in the absence of obesity. Further clinical and basic studies are required to determine the impact of excess dietary sucrose on the developing cardiovascular system.

\section{REFERENCES}

1. DeFronzo RA, Ferrannini E 1991 Insulin resistance: a multifaceted syndrome responsible for NIDDM, hypertension, dyslipidemia, and atherosclerotic cardiovascular disease. Diabetes Care 14:173-194
2. Modan M, Halkin H, Almog S, Lusky A, Eshkol A, Shefi M, Shitrit A, Fuehs Z 1985 Hyperinsulinemia: a link between hypertension, obesity and glucose intolerance. J Clin Invest 75:809-817

3. Zavaroni I, Mazza S, Luchetti L, Buonanno G, Bonati PA, Bergonzan M, Passeri M, Reaven GM 1990 High plasma insulin and triglyceride concentrations and blood pressure in offspring of people with impaired glucose tolerance. Diabet Med 7:494-498

4. Ferrannini E, Buzzigoli G, Bonadonna R, Giorico MA, Oleggini M, Graziadei L, Pedrinelli R, Brandi L, Bevilacqua $S 1987$ Insulin resistance in essential hypertension. N Engl J Med 317:350-357

5. Falkner B, Hulman S, Tannenbaum J, Kushner H 1990 Insulin resistance and blood pressure in young black men. Hypertension 16:36-43

6. Hwang IS, Ho H, Hoffman BB, Reaven GM 1987 Fructose-induced insulin resistance and hypertension in rats. Hypertension 10:512-516

7. Reaven GM 1991 Insulin resistance, hyperinsulinemia, hypertriglyceridemia, and hypertension. Parallels between human disease and rodent models. Diabetes Care 14:195-202

8. Hollenbeck CB, Coulston AM 1991 The effects of increased sucrose consumption on carbohydrate and lipoprotein metabolism in individuals with non-insulin dependent diabetes and other syndromes associated with insulin resistance. In: Kretchmer N, Hollenbeck CB (eds) Sugars and Sweeteners. CRC Press, Boca Raton, FL, pp 203-215

9. Silliman K, Coulston AM 1991 Sugars in the diet. In: Kretchmer N, Hollenbeck CB (eds) Sugars and Sweeteners. CRC Press, Boca Raton, FL, pp 17-36

10. Michel S, Falkner B, Hulman S 1990 Dietary intake of adolescents at risk for cardiovascular disease. J Am Coll Nutr 9:552(abstr)

11. Narimiya M, Azhar S, Dolkas CB, Mondon CE, Sims C, Wright DW, Reaven GM 1984 Insulin resistance in older rats. Am J Physiol 246:E397-E404

12. Buñag RD 1973 Validation in awake rats of a tail-cuff method for measuring systolic blood pressure. J Appl Physiol 34:279-282

13. Smith D, Rossetti L, Ferrannini E, Johnson CM, Cobelli C, Toffolo G, Katz $\mathrm{L}$, DeFronzo $\mathrm{R} 1987$ In vivo glucose metabolism in the awake rat: tracer and insulin clamp studies. Metabolism 36:1167-1174

14. Hulman S, Falkner B, Freyvogel N 1993 Insulin resistance in the conscious spontaneously hypertensive rat: euglycemic hyperinsulinemic clamp study. Metabolism 42:14-18

15. Somogyi MJ 1945 Determination of blood sugar. J Biol Chem 160:69-73

16. Steele R 1959 Influence of glucose loading and injected insulin on hepatic output. Ann NY Acad Sci 82:420-430

17. Cobelli C, Mari A, Ferrannini E 1987 The non-steady state problem: error analysis of Steele's model and new developments for glucose kinetics. Am J Physiol 252:E679-E689

18. Dunn A, Katz J, Golden S, Chenoweth M 1976 Estimation of glucose turnover and recycling in rabbits using various $\left[{ }^{3} \mathrm{H},{ }^{14} \mathrm{C}\right]$ glucose labels. Am J Physiol 230:1159-1162

19. Ferrannini E, Groop LC 1989 Hepatic glucose production in insulin resistant states. Diabetes Metab Rev 5:711-725

20. Shafrir E 1991 Fructose/sucrose metabolism, its physiological and pathological implications. In: Kretchmer N, Hollenbeck CB (eds) Sugars and Sweetners. CRC Press, Boca Raton, FL, pp 63-98

21. Issad T, Coupé C, Ferré P, Girard J 1987 Insulin resistance during suckling period in rats. Am J Physiol 253:E142-E148

22. Olefsky JM, Kolterman OG, Scarlett JA 1982 Insulin action and resistance in obesity and non-insulin dependent type II diabetes mellitus. Am J Physiol 243:E15-E30

23. Stamler R, Stamler J, Reidlinger WF, Algera G, Roberts RH 1978 Weight and blood pressure findings in hypertension screening of 1 million Americans. JAMA 240:1607-1610

24. Storlien LH, Kraegen EW, Jenkins AB, Chisholm DJ 1988 Effects of sucrose vs starch diets on in vivo insulin action, thermogenesis, and obesity in rats. Am J Clin Nutr 47:420-427

25. Thorburn AW, Storlien LH, Jenkins AB, Khouri S, Kraegen EW 1989 Fructose-induced in vivo insulin resistance and elevated plasma triglyceride levels in rats. Am J Clin Nutr 49:1155-1163

26. Reaven GM 1988 Role of insulin resistance in human disease. Diabetes 37:1595-1607

27. Defronzo RA 1981 The effect of insulin on renal sodium metabolism. Diabetologia $21: 165-171$

28. Falkner B, Hulman S, Kushner H 1992 Hyperinsulinemia and blood pressure sensitivity to sodium in young blacks. J Am Soc Nephrol 3:940-946

29. Hwang I-S, Huang W-C, Wu J-N, Shian LR, Reaven GM 1989 Effect of fructose-induced hypertension on the renin-angiotensin-aldosterone system and atrial natriuretic factor. Am J Hypertens 2:424-427

30. Young JB, Landsberg L 1977 Stimulation of the sympathetic nervous system during sucrose feeding. Nature 269:615-617

31. Anderson EA, Bolon TW, Hoffman RP, Sinkley CA, Mark AL 1992 Insulin increases sympathetic activity but not blood pressure in borderline hypertensive humans. Hypertension 19:621-627

32. Cowett RM, Oh W, Schwartz R 1983 Persistent glucose production during glucose infusion in the neonate. J Clin Invest 71:467-475

33. Goldman SL, Hirata T 1980 Attenuated response to insulin in very low birth weight infants. Pediatr Res 14:50-53

34. Hill R, Baker N, Chaikoff IL 1954 Metabolic patterns induced in the normal rat by feeding an adequate diet containing fructose as sole carbohydrate. J Biol Chem 209:705-716 
35. Varma S, Nickerson H, Cowan JS, Hetenyi G 1973 Homeostatic responses to glucose loading in newborn and young dogs. Metab Clin Exp 22:13671375

36. Hulman SE, Kliegman RM 1989 Assessment of insulin resistance in newborn beagles with the euglycemic hyperinsulinemic clamp. Pediatr Res 25:219-223

37. Issad T, Coupe C, Pastor-Anglada M, Ferre P, Girard J 1988 Development of insulin sensitivity at weaning in the rat. Role of nutritional transition. Biochem J 251:685-690
38. Frank GC, Webber LS, Farris RP, Berenson GS 1986 Dietary data book: quantifying dietary intakes of infants, children and adolescents: The Bogalusa Heart Study. From the Nutrition Core, Planning, and Analysis Core Components of the National Research and Demonstration Center: Arteriosclerosis (NRDC-A). Louisiana State University Medical Center, New Orleans. Library of Congress Catalog Card No. 86-51215. New Orleans, LA

39. Kimm SYS, Gergen PJ, Malloy M, Dresser C, Carroll M 1990 Dietary patterns of U.S. children: implications for disease prevention. Prev Med $19: 432-442$

\section{Announcement}

\section{Charles E. Culpeper Foundation Scholarships in Medical Science}

The Charles E. Culpeper Foundation is currently accepting applications for its 1995 Scholarships in Medical Science Program designed to support the career development of academic physicians.

Up to three awards of $\$ 100,000$ per year for 3 years will be made to United States medical schools on behalf of candidates who are U.S. citizens, who have received their M.D. degree from a U.S. medical school in 1986 or later, and who are judged worthy of support by virtue of the quality of their research proposals. All scientific research relevant to human health is eligible for consideration. No institution may nominate more than one candidate.

In selecting awardees, emphasis will be on identifying young physicians with clear potential for making substantial contributions to science as academic physicians. Since January 1988, 21 physicians have been selected as Charles E. Culpeper Foundation Medical Scholars.

Deadline for applications is August 15, 1994. Awards will be announced by January 13, 1995 for activation on or about July 1, 1995. Application forms and instructions may be obtained by contacting the Charles E. Culpeper Foundation at Financial Centre, 695 East Main Street, Suite 404, Stamford, CT 06901. 